\title{
Olive oil and haemostasis
}

\author{
By Colette N.M. Kelly ${ }^{1^{\star}}$, George J. Miller ${ }^{2}$ and Christine M. Williams ${ }^{3}$
}

\author{
${ }^{1}$ Nutrition Consultant, Co. Meath, Ireland \\ ${ }^{2}$ MRC Epidemiology and Medical Care Unit, Wolfson Institute of Preventive Medicine, London, UK \\ ${ }^{3}$ Hugh Sinclair Unit of Human Nutrition, School of Food Biosciences, \\ University of Reading, RG6 6AP, UK
}
"Corresponding author: : Dr. Colette N.M. Kelly. Tel: +353 (0) 872296257
Email: drkelly@kilroenutrition.com

\section{CONTENTS}

1. INTRODUCTION

2. THE HAEMOSTATIC SYSTEM: PLATELETS, COAGULATION AND FIBRINOLYSIS

\subsection{Platelets}

2.1.1. The release reaction and platelet aggregation

2.1.2. Regulation of platelet activation

2.1.3. Platelet function and risk of CVD

2.1.4. Tests to measure platelet aggregation

2.2. Coagulation cascade

2.2.1. The extrinsic and final common pathways

2.2.2. The intrinsic pathway and the kallikrein-kinin (contact) system

2.2.3. Inhibitors of blood coagulation

2.3. The Fibrinolytic system

3. PROTHROMBOSIS AND RISK OF CVD

4. SPECIFIC HAEMOSTATIC RISK FACTORS AND CVD
4.1. Factor VII
4.2. Fibrinogen
4.3. Fibrinolytic factors

4.4. Tests to measure coagulation and fibrinolytic factors

5. THE MEDITERRANEAN DIET

5.1. Platelets and MUFA

5.2. Mechanism of action of MUFA on platelets

5.3. Effects of MUFA on fasting haemostatic factors

5.3.1. Fibrinolytic factors

5.3.2. Fibrinogen

5.3.3. Factor VII

5.4. MUFA-rich test meals and FVII

5.5. MUFA-rich diets and postprandial FVII

5.6. Mechanism of action of MUFA on FVII activation

5.7. Other components in olive oil

5.7.1. Phenolic compounds

5.7.2. Vitamin E

6. CONCLUSION

\section{REFERENCES}

\section{RESUMEN}

\section{Aceite de oliva y la hemostasia.}

El aceite de oliva es un componente esencial de la dieta Mediterránea que puede explicar el bajo índice de enfermedad cardiovascular (CVD) en los países del sur de Europa. El aceite de oliva (extra virgen) es una fuente de ácidos grasos monoinsaturados (MUFA) y de compuestos fenólicos, de gran interés por sus efectos, entre otros, sobre las lipoproteínas y los lípidos plasmáticos, su capacidad antioxidante y su papel en la expresión de factores relacionados con la trombosis. En este capítulo se presenta un resumen del conocimiento actual sobre la influencia derivada del consumo de aceite de oliva (extra virgen) en el sistema hemostático y el riesgo de CVD. Por ahora se sabe que dietas ricas en MUFA (aceite de oliva) pueden atenuar la respuesta trombótica mediante la reducción de la agregación plaquetaria y de las concentraciones postprandiales del factor VII de coagulación (FVII). La trombosis es un evento relevante en los ataques al corazón y el ictus, de manera que su modulación con la dieta puede constituir una forma rentable para la disminución de la incidencia de CVD en poblaciones que consumen dietas enriquecidas en MUFA/aceite de oliva durante largo tiempo.

PALABRAS-CLAVE: Aceite de oliva; Ácidos grasos monoinsaturados; Hemostasia; Factor VII; Plaquetas; Fenólicos; Fibrinolisis; Dieta Mediterránea.

\section{SUMMARY}

\section{Olive oil and haemostasis.}

Olive oil is a key component of the traditional Mediterranean diet; a diet that may explain the low rate of cardiovascular disease (CVD) in Southern European. (Extra virgin) Olive oil is a good source of monounsaturated fatty acids (MUFA) and phenolic compounds, both of which have been investigated for their effects on plasma lipids and lipoproteins, measures of oxidation and factors related to thrombosis. This issue aims to summarise the current understanding of the effects of such dietary components on the haemostatic system and subsequent risk of CVD. To date, evidence suggests that diets rich in MUFA and thus in olive oil attenuate the thrombotic response via a reduction in platelet aggregation and in postprandial FVII levels. Thrombosis is a key event in causing heart attacks and strokes, which if modulated by diet could pose a cost-effective way of reducing CVD incidence in populations that adhere to MUFA/olive oil-rich diets long-term.

KEY-WORDS: Olive oil; Monounsaturated fatty acids; Haemostasis; Factor VII; Platelets; Phenolics; Fibrinolysis; Mediterranean diet.

\section{INTRODUCTION}

Cardiovascular disease (CVD) is the main cause of death in Europe accounting for over 4 million deaths each year; about half of which are from coronary heart disease (CHD) and nearly a third from stroke (Rayner and Peterson, 2000). Mortality rates vary between population groups, for example, Southern European countries generally have lower $\mathrm{CHD}$ death rates compared to the rest of Europe. Death rates from stroke tend to be higher in Central 
and Eastern Europe than in Northern, Southern and Western Europe.

CVD is not only a major cause of death but also contributes to ill health and disability. The number of people suffering from CVD (e.g. angina) in some European countries (e.g. UK) may even be rising because of the ageing population and improvements in treatment. Thus, the health care costs for the (rising) number of CVD patients are economically unsustainable. Consequently, public health measures, such as improvements in diet and physical activity levels are of paramount importance.

It is estimated that up to $30 \%$ of deaths from CHD are due to unhealthy diets (National Heart Forum, 2002). The lower rate of CVD in Southern Europe suggests a potential role of the traditional Mediterranean diet in the prevention of CVD. In fact, the Mediterranean diet has become a cultural model for dietary improvement. It is characterised by the use of olive oil as the major culinary fat, which is rich in monounsaturated fatty acids (MUFA). In addition, extra virgin olive oil contains a number of phenolic compounds, for example, hydroxytyrosol and oleuropein, which via their antioxidant and other potent biological activities could partially account for the observed healthful effects of the traditional Mediterranean diet.

The effects of olive oil on blood lipids and CVD risk have been reviewed elsewhere in this supplement. The aim of this issue is to focus on the effects of olive oil on haemostasis and subsequent risk of CVD. The evidence for an effect of olive oil on haemostasis is not as extensive as for lipids but is interesting and warrants discussion. As a prelude to this, the intricate haemostatic system will be described and the associations between various blood clotting factors and risk of CVD will be reviewed.

\section{THE HAEMOSTATIC SYSTEM: PLATELETS, COAGULATION AND FIBRINOLYSIS}

The haemostatic system is essential for the preservation of life, providing protection after wound injury by controlling bleeding and playing a role in tissue repair. The system comprises of the endothelium of the blood vessel wall, platelets, the coagulation and fibrinolytic systems (and their co-factors) and their plasma inhibitors.

The central step in stable clot formation is the generation of the enzyme thrombin, which converts the soluble protein fibrinogen to its insoluble product, fibrin. The central role of thrombin is illustrated by the fact that thrombin has more than 20 substrates in the haemostatic system, including triggering the activation and aggregation of platelets.

The sequence of events that culminates in the formation of a blood clot after injury can also occur with rupture of an atheromatous plaque, resulting in clot formation in the lumen of the vessel, a condition known as thrombosis. This becomes problematic if the lumen is partially or completely occluded because blood flow to vital organs such as the heart and brain is interrupted or obstructed.

For the purpose of this review, the haemostatic system will be divided into 3 phases: platelets, coagulation and fibrinolysis. However, the events to be described do not occur sequentially. In fact, tissue damage activates both platelets and the coagulation cascade simultaneously. Moreover, events are not ranked in order of significance.

\subsection{Platelets}

Platelets are small cell fragments that are produced by the disintegration of megakaryocytes, the large precursor cells found in bone marrow (Baboir and Stossel, 1990a). On release into the circulation they circulate for approximately $9-12$ days and the normal platelet count varies widely (140-440 $\left.\times 10^{9} / \mathrm{L}\right)$

The resting (unactivated) platelet has a discoid shape with smooth, convex surface contours. Random indentations are also present representing sites of communication between channels of the surface-connecting or open canalicular system, and the exterior of the cell. It provides access to the interior for plasma-borne substances and a route for products of the "release reaction" (see below). Platelet activation is accompanied by anatomical changes including centralisation of the storage granules, formation of pseudopodia and shape change (from discs to spheres). Increased exposure of fibrinogen binding sites is one of the earliest events in platelet activation. Structural changes also occur in other platelet membrane receptors, which enables binding of other adhesive proteins such as von Willebrand factor (vWF), vitronectin and fibronectin.

The adhesion of platelets to exposed subendothelial tissue following vascular injury is a crucial part of the initial events of haemostasis. Collagen is the main structural protein in the vessel wall and it supports platelet adhesion (via receptors present on the platelet) and activation. Once bound to platelet receptors, both collagen and thrombin trigger platelet synthesis of prostaglandins from cell membrane arachidonic acid (AA, 20:4n-6). The product, thromboxane $A_{2}\left(T \times A_{2}\right)$ is a potent vasoconstrictor and initiates the release reaction, thereby encouraging aggregation of activated platelets.

\subsubsection{The release reaction and platelet aggregation}

Once adsorbed to the damaged site, platelets swell and release many of their cellular constituents 
into the ambient blood. The dense granules contain 5-hydroxytryptamine (5-HT), noradrenaline, ATP, ADP and calcium, which affect other platelets and vasomotor responses. The $\alpha$-granules contain a range of proteins including platelet-derived growth factor (PDGF), fibrinogen, Factor V, vWF, platelet factor 4 and $\beta$-thromboglobulin. These influence the adhesion of platelets to one another and to the endothelium as well as other platelet properties.

\subsubsection{Regulation of platelet activation}

To regulate the extent of the platelet response and to prevent the inadvertent threat of platelet thrombus and embolus formation a regulatory mechanism is necessary. This is provided by the surrounding endothelium, permitting blood flow restoration. The platelets also contribute to the repair mechanism by releasing PDGF and platelet-derived endothelial growth factor (PDEGF), which encourages repair of the endothelium.

Stimulated endothelial cells release inhibitory agonists, which include certain prostaglandins $\left(\mathrm{PGI}_{2}\right)$, nitric oxide and adenosine. These vasodilators inhibit platelet aggregation, promote disaggregation, and inhibit platelet adhesion to the endothelium. Interestingly, the opposing effects of the prostanoids $\mathrm{TxA}_{2}$ (agonist) released by platelets, and $\mathrm{PGI}_{2}$ (antogonist) released by endothelial cells, have led to the concept that the extent of platelet recruitment after vessel-wall injury is a function of the ratio of the concentrations of these opposing factors. In addition the chemical form and biopotency of the thromboxane and prostacylcin formed by platelets and endothelial cells is dependent upon the nature of the precursor polyunsaturated fatty acid (PUFA) from which they are derived. Dietary fat interventions that alter the composition of the membrane fatty acid precursors have the potential to alter platelet aggregation and potentially thrombosis risk (BNF, 1992).

In summary, platelets circulate passively and do not adhere to intact endothelium. However, in response to agonists released from damaged vessel walls (e.g. ADP, thrombin, serotonin), and following the exposure of collagen, platelets rapidly undergo the process of adhesion, shape change, secretion and aggregation. Activation is a result of occupancy by agonists of receptors on the platelet plasma membrane that continues until the constricted lumen of the small vessel is completely occluded by a loose aggregate of platelets (Kroll and Schafer 1989). This is transformed into a more definite plug by the activation of the blood clotting mechanism.

\subsubsection{Platelet function and risk of CVD}

An increase in the sensitivity of platelets to activation is strongly suspected in those at risk of
CVD. However, this has been difficult to prove using established platelet function tests, e.g. aggregometry because of the sensitivity of blood platelets to handling. Nevertheless, marked reductions in coronary events with aspirin use provide support for the role of platelets in CHD (The anti-platelet trialists' collaboration, 1994; 2002). Aspirin is now used prophylatically for thrombotic disorders and is standard treatment for patients with both cardiovascular and cerebrovascular disease (George, 2000). Aspirin irreversibly acetylates the amino terminal serine in the active site of the enzyme cyclooxygenase, resulting in the reduced formation of the cyclic endoperoxide intermediates and the final products of AA metabolism, e.g. the platelet stimulating agent $\mathrm{TxA}_{2}$ (Patrono et al., 1980). The effect persists for the lifespan of the platelet. There are more drugs that target platelet activation, e.g. clopidogrel prevents platelet activation by ADP, an agonist that enhances the activity of other platelet agonists (Payne et al., 2002) and there are a number of agents that block the platelet fibrinogen receptor, GPIlb/IIla (Topol et al., 1999).

\subsubsection{Tests to measure platelet aggregation}

Despite the scope of the methodology to investigate platelet function, platelet aggregation measured in whole blood or platelet rich plasma (PRP) is routinely used because it is relatively simple to perform. Moreover, it is a good measure of the inhibition of platelet function, e.g. the administration of aspirin or more potent antiplatelet drugs in vivo results in demonstrable inhibition of the aggregation response ex vivo to various agonists (Fitzgerald and Barry, 1997). It is probably for this reason that such a test has been used extensively to monitor platelet status in both epidemiologic studies and clinical trials. In fact, in dietary intervention studies it is the most popular method of choice.

The application of this technique is based on the premise that increased in vitro platelet aggregation indicates an increased tendency for thrombogenesis in vivo. It involves the addition of aggregating agents (agonists) to whole blood/PRP and the extent of aggregation will vary depending on the aggregating agent and their concentration. Agonists that are commonly used include ADP, thrombin, collagen, $\mathrm{TxA}_{2}$, epinephrine and $\mathrm{AA}$.

In a recent study neither the PRP nor whole blood aggregometry techniques showed any predictive power for myocardial infarction, but were better for stroke (Elwood et al., 2001). However, earlier work in a smaller cohort suggested that spontaneous aggregation (without agonists) of platelets in those with CVD was predictive of cardiac events and mortality (Trip et al., 1990). Thus, the predictive value of ex vivo platelet aggregation remains questionable. 
The lack of adequate and robust tests is a major hindrance in determining the predictive power of platelet function for CVD. There a number of other tests to choose from, e.g. the analysis of eicosanoids such as $\mathrm{TxB}_{2}$ (metabolic product of $\mathrm{TxA}_{2}$ ) and the prostaglandin 6 keto $F_{2 a}$ (metabolic product of prostacyclin). Both can be measured in blood and urine but their predictive power has not been elucidated yet. A relation between these markers and the likelihood of a subsequent event is a prerequisite for using them to define a pro-thrombotic state (see below).

\subsection{Coagulation cascade}

The coagulation system is a proteolytic cascade that is under very strict regulatory control provided by positive and negative feedback loops (Figure 1). In the healthy state, the pathway exhibits low-level basal "steady state" activity, which primes the system, holding it ready for a response within seconds of injury. The liver produces most of the clotting factors, and several of them [factors II (FII), VII (FVII), IX (FIX), and X (FX)] need vitamin $\mathrm{K}$ for production. Vitamin $\mathrm{K}$ is also needed to produce protein $\mathrm{C}$ and protein $\mathrm{S}$, which are natural anticoagulants.

Upon injury, a series of linked reactions follows in which a serine protease, once activated, is free to activate its downstream substrate. By convention, each clotting factor or zymogen of the coagulation



Figure 1

The Coagulation Pathway (classical description). In the classical description, exposure of blood to non-membranous surfaces and of negative charge activates the intrinsic pathway. The extrinsic pathway is activated when blood contacts with cell membranes exposing tissue factor (TF). The sequential proteolytic transformations are dependent of phospholipids and take place on cell membrane surfaces.

HMK, high-molecular-weight kininogen

$\mathrm{TM}$, thrombomodulin

$\rightarrow$, coagulant activity

$\rightarrow$, anticoagulant activity

ubscript "a" denotes the enzyme product of the zymogen precursor protein $\square$, FX converting complex and prothrombin converting complex, respectively pathway is given a roman numeral, and its activated form is donated by the subscript "a". Davie and Ratnoff (1964) and Macfarlane (1964) originally described these proteolytic transformations as a waterfall sequence and cascade, respectively. This process culminates in the generation of thrombin, the enzyme that converts fibrinogen to fibrin, as well as activating platelets. The action of thrombin on its substrates is in a time- and concentration-ordered manner to augment coagulation, bring it to completion, prevent premature dissolution of the clot (fibrinolysis), and return the system to its basal state (in press).

The conversion of prothrombin to thrombin is mediated by $\mathrm{FXa}$, which itself is activated either by FVIla of the extrinsic pathway or FIXa of the intrinsic pathway. Thus, there are two alternate routes for the generation of FX as well as the final common pathway, which results in thrombin formation. Note that these components of the overall pathway do not act in isolation, for there are many cross-reactions and back-reactions between them, which provide auto-regulation.

\subsubsection{The extrinsic and final common pathways}

The extrinsic system is essentially the principal initiating pathway of in vivo blood coagulation and involves both blood and vascular elements. The coagulation of plasma is triggered when a protein called tissue factor or thromboplastin, which is normally embedded in the plasma membrane of cells, is exposed to blood. This occurs upon vessel wall injury, which can be traumatic, inflammatory or immunological in character (in press).

Factor VII then binds to exposed tissue factor and undergoes a single cleavage to its active enzyme, FVIla. FIXa, FXa and FVIla can also cleave FVII. A tissue factor-factor VIla complex forms, which activates FX and FIX. Plasma FXa is the first molecule of the common pathway and in association with $\mathrm{FVa}$, generates thrombin from prothrombin, which as noted earlier has numerous substrates, (e.g. FV, FVIII, FXIII, fibrinogen and platelets). Plasma FIXa, with its co-factor vWf-FVIIla, also activates FX.

Clot formation begins with the thrombin-catalysed conversion of fibrinogen to fibrin. The clot is held together by weak noncovalent forces at first, until the action of FXIIla, a cross-linking enzyme, resulting in covalently held strands and a mature clot. The fibrin matrix not only acts as a sealing of the wound, but also facilitates the repair process by providing a scaffold for cell invasion and angiogenesis.

\subsubsection{The intrinsic pathway and the kallikrein- kinin (contact) system}

The kallikrein-kinin system (previously referred to as the contact system) comprises of factor XII (FXII), 
factor XI (FXI), prekallikrein (PK) and high molecular weight kininogen (HMWK). For many years, it was thought that these proteins interact upon binding to negatively charged surfaces, such as collagen, heparans, and free fatty acids, which results in several activation products (e.g. FXIla and FXla) and ultimately the activation of FX. More recently, a new hypothesis has emerged suggesting that HMWK, which circulates in plasma in a complex with $\mathrm{PK}$ and FXI, binds a multiprotein receptor complex on endothelial cells. This results in the conversion of PK to kallikrein, by the membrane-expressed enzyme prolycarboxypeptidase (Schmaier, 2002). Kallikrein autodigests its receptor, liberating the vasoactive, proinflammatory mediator bradykinin, and activates FXII (Shariat-Madar et al., 2002). Increased levels of FXII activate FXI. The action of FXla and thrombin (via feedback) generate FIXa, which, in concert with its co-factor (vWf-FVIIIa) activates FX, which feeds into the common pathway already described.

\subsubsection{Inhibitors of blood coagulation}

Coagulation inhibitors are necessary to ensure that thrombin generation remains limited and localised. In summary, for every procoagulant response, there is an anticoagulant mechanism. Tissue factor pathway inhibitor (TFPI) neutralises the extrinsic pathway; heparin is a cofactor for antithrombin III, which inhibits all of the serine proteases of the clotting cascade (except FVIIa); alpha-1 antitrypsin is an inhibitor of the kallikrein-kinin system of coagulation; and protein C is converted to its activated form by endothelial bound thrombomodulin, and once activated, works with Protein $S$ to inactivate the cofactors FVa and FVIIla. There are more circulating and cell-bound proteins that inhibit coagulation but they are not discussed in this review because of the scarity of data in relation to CVD risk and intervention by diet.

\subsection{The Fibrinolytic system}

The fibrinolytic mechanism prevents excessive fibrin accumulation by promoting local dissolution of thrombi and promoting wound healing by re-establishment of blood flow. Thus, the breakdown of the fibrin clot by plasmin is necessary to make way for repair of the damaged vessel.

Fibrinolysis involves the conversion of plasminogen to plasmin by the action of plasminogen activators, e.g. tissue plasminogen activator (t-PA) and urokinase plasminogen activator (u-PA) (Marckmann, 1995). The activities of plasmin and t-PA, are regulated by alpha2-antiplasmin and plasminogen activator inhibitor-1 (PAI-1), respectively (Mann, 1997), thus preventing excess fibrinogen degradation by plasmin. Both PAI-1 and alpha2-antiplasmin also inhibit activated protein C, thus increasing thrombin generation, platelet aggregation and fibrin formation. Thrombin activatable fibrinolysis inhibitor (TAFI) (also known as procarboxypeptidase $B$ ) is a recently discovered inhibitor of fibrinolysis. As the name suggests TAFI is activated by high concentrations of thrombin generated after clot or thrombus formation. In addition, low concentrations of thrombomodulin augment the generation of activated TAFI. The digestion of a clot by plasmin results in fibrin-split products, which are themselves, potent inhibitors of clotting (Babior and Stossel, 1990b).

In summary, the clotting cascade is a series of linked biochemical reactions that result in the formation of a durable fibrin clot. Blood coagulation is initiated by membrane bound tissue factor, and is amplified through the intrinsic pathway by mechanisms that provide crosstalk and feedback. Virtually all of the coagulation reactions take place on activated cell surfaces and, in some cases, accelerate by the presence of a cofactor (FVa and FVIIla). Haemostasis can be considered a finely tuned balance between procogulant and anticoagulant forces. Clinical phenotypes, namely bleeding or thrombosis, arise when the scale is tipped towards one side or the other (Aird, 2003).

\section{PROTHROMBOSIS AND RISK OF CVD}

A "pro-thrombotic" state encompasses a change in any component of the haemosatic system that raises the risk of thrombosis e.g. increased sensitivity of platelets to activation or an imbalance in thrombin's diverse roles. In other words, the pro-thrombotic state exists when there is an imbalance between coagulability and fibrinolytic capacity that favours fibrin deposition and clot formation. Although a single measure of the pro-thrombotic state would be ideal, it does not exist. Clinical markers of prothrombosis have included raised levels of fibrinopeptide A (a marker of thrombin's action on fibrinogen) and decreased levels of D-dimer (a marker of fibrin turnover). At present, these measures are impractical for epidemiological studies. Instead, markers of platelet activation, changes of the vascular endothelium (t-PA and PAl-1) and the clotting cascade have been investigated as potential risk factors for CVD. It should be recognised that a pro-thrombotic state could exist without necessarily leading to thrombosis in the same way that not everyone with a high blood cholesterol level suffers a myocardial infarction.

Risk factor modificiation serves to ameliorate the pro-thrombotic state and reduce atherothrombotic events. The established haemostatic risk factors that are associated with CVD and modifiable by MUFA-rich diets such as olive oil are discussed 
below. Only data relating to human studies will be discussed.

\section{SPECIFIC HAEMOSTATIC RISK FACTORS AND CVD}

\subsection{Factor VII}

Results from the first Northwick Park Heart Study (NPHS) conducted in the 1970s in England provided the impetus for further investigation into the role of FVII in CHD. Plasma FVIIc, a functional measure of the combination of circulating concentrations of FVII and FVIla, was identified as a marker of risk of fatal (but not non-fatal) CHD (Meade et al., 1986). Surprisingly, NPHS-II undertaken in the 1990s did not identify FVIlc as a risk factor, which could be explained by the decrease in dietary fat intake over the intervening years (Cooper et al., 2000). Other studies have failed to show FVIlc as a risk factor for CHD (Tracy et al., 1999), which indicates that raised FVIIc is not a consistent CHD risk factor.

Typically, FVIla rises postprandially but this seems to have no influence on the basal generation of thrombin (Bladbjerg et al., 2000). However, since FVIla-tissue factor complex is responsible for the initiation of the coagulation cascade, increased generation of FVIla in the postprandial state would increase the potential for thrombin production in the event of plaque rupture with exposure of tissue factor to blood (Silveira, 2001).

\subsection{Fibrinogen}

Many studies have found fibrinogen to be a predictor of CHD (Meade et al., 1993; Mann, 1997; Heinrich et al., 1994; Cooper et al., 2000; Tracy et al., 1999) and it is also an established risk factor for thrombotic stroke (Wilhelmsen et al., 1984). Yet the precise pathophysiological relation of fibrinogen and risk of CHD is unknown. Atherosclerosis could secondarily cause an increase in fibrinogen because it is an acute-phase protein and fibrinogen has been associated with changes in other acute phase proteins including C-reactive protein (CRP) (Kuller et al., 1996). Either way, increased fibrinogen concentrations could adversely affect plasma viscosity and platelet aggregability.

Fibrinogen concentration is associated with several other cardiovascular risk factors; it increases with age, $\mathrm{BMI}$ and smoking and is elevated in postmenopausal women. Physical activity is inversely associated with fibrinogen and females have higher levels than males (Meade et al., 1985; 1979).

\subsection{Fibrinolytic factors}

Indirect measures of fibrinolysis (e.g. dilute blood clot lysis time) have shown positive associations with
CHD (Meade et al., 1993). More direct measures of hypofibrinolysis (using t-PA antigen, PAl-1 antigen and activity) are also positive risk factors for $\mathrm{CHD}$ (Hamsten et al., 1985; 1987; Ridker et al., 1993). PAl-1 has been positively associated with risk factors associated with syndrome $\mathrm{X}$, namely central obesity, high triglyceride concentrations, low HDL-cholesterol, hyperglycaemia and low physical activity (Dawson and Henney, 1992). Finally, Ridker et al. (1994) have reported that the mean concentration of t-PA antigen is higher among men at increased risk of stroke than in those not at risk.

Overall, the evidence for associations with CVD is strongest for fibrinogen. Intervention by diet has focused on FVII, with less emphasis on fibrinogen and fibrinolytic factors.

\subsection{Tests to measure coagulation and fibrinolytic factors}

In order to obtain reproducible results, haemostatic factor assays need to be performed with considerable care. One of the main concerns is prevention of in vitro artifacts that can significantly alter the assay results. These include the quality of the venepuncture, the sample processing procedures, choice of anticoagulant and plasma storage conditions (Bauer, 1993). Considerations of these factors are a prerequisite for coagulation studies.

Discrepancies in results between laboratoires can sometimes be ascribed, at least in part, to the choice of method employed. Although assays for FVIla, FVII antigen (FVIlag), fibrinogen and t-PA are now routine, there has been considerable debate about the best method to use for FVII analysis. Furthermore, there was some concern about the considerable inter-laboratory variation in PAI-1 levels determined with commercial kits, especially for assays measuring activity levels (Marckmann, 1995).

\section{THE MEDITERRANEAN DIET}

There is a consensus on what constitutes a traditional Mediterranean diet: plenty of fresh vegetables, fruit, grains and olive oil with moderate consumption of wine (mainly red wine) and dairy products (mainly cheese). However, there is considerable debate about the nutrients responsible for the purported health effects of such a diet. The low saturated/high MUFA content has received considerable attention. Olive oil contains $73 \%$ MUFA of which all but $1 \%$ is oleic acid $(18: 1 n-9)$. It contains $14.3 \%$ saturated fatty acids (SFA) and 8.2\% PUFA (MAFF, 1998). Rapeseed oil contains $59 \%$ MUFA, $7 \%$ SFA, 29\% PUFA, and has been used in many intervention studies to investigate the benefits of MUFA-rich diets, particularly in Northern 
Europe because it is more economical than olive oil. Nevertheless, it is assumed that the effects observed with rapeseed oil would apply to diets rich in olive oil.

Previous research concerning protective cardiovascular properties of olive oil has focused on the beneficial consequences on blood cholesterol levels of substituting dietary SFA with oleic acid. However, the lower rate of CHD in Southern Europe compared to Northern parts could be attributable, at least in part, to the anti-thrombotic effects of MUFA-rich diets. Of course, it is also possible that antioxidants and other phytochemicals have a role to play in the contribution to CVD risk but the following section will focus on the evidence for an effect of MUFA-rich diets on haemostatic factors.

\subsection{Platelets and MUFA}

It is perhaps not surprising that dietary fats, which may alter the composition of the platelet membrane, would affect their function since many of the events that occur during platelet activation are membrane dependent. However, the data illustrating changes in platelet aggregation in response to changes in fat composition are equivocal. Sirtori et al. (1986) reported significant decreases in aggregation in response to collagen and $A A$ when olive oil diets containing $17.5 \%$ energy as MUFA were administered for 8 weeks. Likewise, Barradas et al. (1990) found that olive oil supplementation (21g/day for 8 weeks) to healthy volunteers reduced platelet aggregation induced by ADP and collagen. More recently, in a population of young healthy adults, consumption of a MUFA-enriched diet in comparison to a diet rich in SFA, resulted in a significant decrease in whole blood platelet aggregation at 8 weeks in response to ADP, collagen and $A A$, which was maintained at 16 weeks in response to ADP (Figure 2; Smith et al., 2003). Importantly the source of MUFA in this study was based on refined olive and rapeseed oil, eliminating the possibility that these effects were due to other constituents different to triglycerides. Notably the effects observed on whole blood platelet aggregation are not large, but they may be important when translated to whole population shifts in SFA and MUFA intakes. In contrast, McDonald et al. (1989), Freese et al. (1994) and Vicario et al. (1998) found no significant change in aggregation when the MUFA content of the diets was increased, whereas Mutanen et al. (1992) and Turpeinen et al. (1998) found that oleic acid- and linoleic acid-rich diets enhanced ADP- and collagen-induced aggregation respectively, when compared to diets rich in SFA. Discrepancies between results may relate to study design, the MUFA content of the diet, dietary control, the concentration and types of agonist employed and

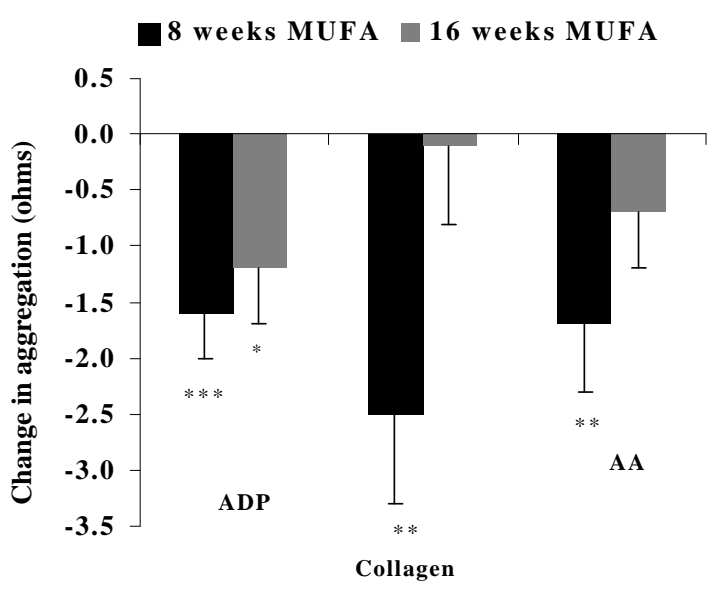

Figure 2

Changes in whole blood platelet aggregation in response to ADP $(10 \mu \mathrm{M})$, collagen $(4 \mu \mathrm{g} / \mathrm{mL})$ and arachidonic acid

(AA) $(1 \mathrm{mM})$ after 8 weeks and 16 weeks of dietary MUFA intervention. Mean values and SEM $(n=29)$.

study duration. The weight of the evidence suggests potential modest beneficial effects of MUFA-rich diets, such as olive oil on platelet aggregation.

\subsection{Mechanism of action of MUFA on platelets}

At least two processes are likely to be involved for fatty acids to regulate platelet function; modulation of the pool of precursor fatty acids and their competitors, with subsequent effects on eicosanoid metabolism; and a change in cell membrane fluidity as a result of which the activity and/or efficiency of receptors can be modulated (Hornstra and Rand, 1986; Mutanen, 1997).

In addition, there is evidence both in favour of (Carvalho et al., 1974; Aviram and Brook, 1982; Stuart et al., 1980) and in contrary to (Joist et al., 1979) the idea that the plasma lipoprotein environment might influence platelet reactivity. In support of this theory, cholesterol-lowering drugs have been shown to reduce platelet activation markers significantly, in addition to reductions in total and LDL-cholesterol levels (Huhle et al., 1999; Hussein et al., 1997). There is also evidence that low levels of oxidation in LDL enhance platelet activity (Siess et al., 1999). An enriched MUFA diet prevents LDL oxidative modifications more than an enriched PUFA diet. Finally, the lipid (e.g. cholesterol) and fatty acid composition of platelets appears to be different in patients with CVD compared to healthy controls (Noula et al., 2000). Thus, improvements in the plasma lipid profile in response to MUFA-rich diets could benefit platelet reactivity. 


\subsection{Effects of MUFA on fasting haemostatic factors}

\subsubsection{Fibrinolytic factors}

Few studies have been undertaken to determine the effects of MUFA on fibrinolytic factors. The Uppsala Longitudinal Study reported that PAI-1 activity was positively related to habitual MUFA and PUFA intake, but not to SFA consumption (Byberg et al., 2001). However, favourable effects on PAI-1 levels have been suggested based on intervention studies (Lopez-Segura et al., 1996; Temme et al., 1999; Avellone et al., 1998). Yet other work indicates no benefit from MUFA-rich diets on PAI-1 levels (Tholstrup et al., 1999; Turpeinen and Mutanen, 1999) and t-PA activity (Lopez-Segura et al., 1996; Tholstrup et al., 1999; Smith et al., 2003). Studies also show that MUFA-rich diets have no effect on TFPI, Fragment 1+2 (Larsen et al., 1999), plasminogen or alpha-2 antiplasmin (Lopez-Segura et al., 1996; Temme et al., 1999). Thus far, intervention studies clearly show no adverse effects from MUFA-rich diets on fibrinolysis. Beneficial effects may occur in some situations but for the general population, improvements in fibrinolytic markers are not guaranteed. To obtain definite answers, long-term prospective studies with clinical end points are ideal, but expensive and impractical. It is possible that intervention studies have not used the best marker for fibrinolytic activty, which provides the impetus for further work to investigate the extent of an effect of MUFA-rich diets, such as those rich in olive oil on fibrinolytic factors.

\subsubsection{Fibrinogen}

Of all the haemostatic factors linked with CVD, the evidence is probably strongest for fibrinogen yet it appears to be unchanged by dietary unsaturated fatty acids of which most studies concentrated on fish oil enrichment (BNF, 1992). Similarly, recent dietary intervention studies using MUFA-rich diets found no change in fibrinogen concentration (Turpeinen and Mutanen, 1999; Smith et al., 2003; Avellone et al., 1998).

\subsubsection{Factor VII}

There have been a number of studies investigating the effects of dietary fat on FVII, particularly because of the positive association between FVII and plasma TAG concentration in the non-fasting and fasting states (Mitropoulos et al., 1989). With improved methods of measurement, it has become clear that diets habitually rich in fat result in an increase in the concentration of fasting FVIlag (Miller et al., 1995). In the majority of studies, different fatty acid classes (SFA, MUFA, PUFA, trans) do not significantly affect the concentration of fasting FVII levels (Heinrich et al., 1990; Foley et al., 1992; Marckmann et al., 1998; Finnegan et al., 2003; Sanders et al., 2003). Similarly, a more recently completed study involving young healthy subjects who consumed a SFA-rich diet for 8 weeks immediately followed by a MUFA-rich diet for 16 weeks found no change in fasting FVIlc or FVIlag levels (Smith et al., 2003). However, Lindman and colleagues (2003) report higher levels of fasting FVIla after a high SFA diet compared a high-unsaturated fatty acid diet; each diet was consumed for 3 weeks in a cross-over design. Moreover, there are a few studies suggesting beneficial effects on fasting variables after MUFA-rich diets. Turpeinen and Mutanen (1999) and Temme et al. (1999) found more favourable effects on FVII levels with oleic acid than linoleic acid- and SFA-rich diets, respectively. Larsen et al. (1999) found a reduction in fasting FVIIc and FVIla following consumption of olive oil and rapeseed oil-enriched diets compared to a habitual diet rich in SFA. Finally, a "Mediterranean type" diet produced significant reductions in fasting FVIlc in those living in urban areas whereas there were significant increases in FVIlc in the rural population when they consumed the "urban type" diet (Avellone et al., 1998). Obviously the effects of the latter study cannot be attributed to the use of olive oil but suggest benefits of a Mediterranean style diet on haemostasis. Thus, there is a consensus that MUFA-rich diets do not have unfavourable effects on haemostasis and for the population at large the current evidence suggests a neutral role of MUFA-rich diets on fasting haemostatic variables.

However, Zilversmit (1979) made the point that man is mostly non-fasting and that postprandial biochemical events have a strong impact on human physiology, including atherogenesis and thrombogenesis. The effects of MUFA on postprandial activation of FVII after test meals rich in MUFA (acute) and after habitual diets rich in MUFA (chronic) appear conflicting and warrant discussion.

\subsection{MUFA-rich test meals and FVII}

The transient increase seen in FVIlc after a fat rich meal is due mainly to a rise in the concentration of FVIla (Miller et al., 1991; Silveira et al., 1994; Salomaa et al., 1993). The composition of dietary fat can influence postprandial levels of FVII.

Earlier work demonstrated that fats rich in MUFA do not differ from fats rich in PUFA or SFA with regard to acute effects on postprandial FVII. Freese and Mutanen (1995) observed no differences between rapeseed oil, sunflower oil, and butter oil with regard to postprandial FVIIc and plasma 
triglyceride responses. Larsen et al. (1997) found similar increases in plasma triglycerides, FVIIc and FVIla after test meals rich in olive oil, rapeseed oil, palm oil, sunflower oil, or butter. Roche and Gibney (1997) specifically investigated the effect of meals with varying MUFA content $(12 \%, 17 \%$ and $24 \%$ of energy) on postprandial FVII activation. Although there was no difference in the extent of activation of factor VIIc between meals, peak postprandial factor VIla was attained significantly earlier following the high-MUFA meal compared with the low-MUFA meal and fasting activity levels were quickly restored. The implications of this pattern of FVII activation are not clear but could attribute to a less thrombotic state. In contrast, concern was expressed about the effects of MUFA on CVD after more pronounced responses of FVIlc to test meals rich in MUFA compared to meals rich in SFA were reported by Oakley et al. (1998). In support of the latter study, a high-palmitic acid meal did not lead to any postprandial change in FVllc whereas it was significantly increased 6 hours from fasting after a high-oleic acid meal (Sanders et al., 1999). Moreover, the increase in FVIla concentrations after the high-palmitic acid meal was half that seen after the high-oleic acid meal.

Initially these two studies may cause alarm with respect to the proposed benefits of olive oil and diets rich in MUFA on haemostasis. However, repeat test meal studies do not convey any information about the effects of habitual diets; rather they divulge important mechanistic information. Therefore, caution should be exercised when interpreting the results of test meal studies in terms of implications for public health. Furthermore, the findings of Oakley et al. (1998) and Sanders et al. (1999) are in contrast with more recent reports that demonstrate lower levels of postprandial FVIla when subjects consume background diets that are high in MUFA (discussed below).

\subsection{MUFA-rich diets and postprandial FVII}

Interest in diets habitually rich in MUFA was re-ignited when the postprandial response to dietary fat was found to be different between Northern and Southern European populations. For example, Southern Europeans experienced a more rapid peak in postprandial triglyceride levels but concentrations quickly returned to preprandial levels (Zampelas et al., 1998). Moreover, although no significant effect of test meal composition was found (SFA v's MUFA) FVIlc was significantly greater 8 hours postprandially in Northern Europeans than in Southern Europeans (Zampelas et al., 1998). The difference in response was also observed in an 8-weeks crossover dietary intervention study where approximately $40 \%$ of SFA were replaced with MUFA (Roche et al., 1998). In response to a standard olive oil test meal postprandial FVIla and FVIlag were significantly lower after the MUFA diet than after the SFA diet. Data from Larsen et al. (1999) contribute to the potential beneficial effect of MUFA-rich diets. Diets rich in olive oil, rapeseed oil and sunflower oil were administered for 3-weeks periods. The olive oil diet was associated with lower nonfasting mean and peak concentrations of FVIla than was the sunflower oil diet. Although not statistically significant, nonfasting mean and peak concentrations of FVIla also tended to be lower after the olive oil diet than after the rapeseed oil diet. A long-term dietary intervention study (16 weeks) has confirmed the effects described above (Silva et al., 2003). Compared with an SFA-rich diet, consumption of a MUFA-rich diet for 16 weeks was associated with significantly lower postprandial FVIIc; the response of FVIla was also lower but did not reach statistical significance. The beneficial effects of adopting a MUFA-rich diet were sustained long-term, which illustrates that there is no attenuation through adaptation.

Taken together, these data demonstrate beneficial effects of diets rich in MUFA, e.g. olive oil and contribute to the explanation for lower rates of $\mathrm{CHD}$ in countries whose diets are habitually rich in MUFA, such as Southern Europe.

\subsection{Mechanism of action of MUFA on FVII activation}

The mechanism whereby dietary fat leads to activation of FVII has been thoroughly investigated but remains uncertain (in press). Advancement in this area was hampered in earlier years because of the number of different tests used to measure FVII both between and within studies. Nevertheless, hypotheses evolved from in vitro work, which in some cases were refuted once human studies were performed (Miller et al. 1996). It does appear from studies in vivo with specific coagulation factor-deficient patients that FIX is essential for the postprandial activation of FVII (Silveira, 2001). Furthermore, the idea that the type of lipoprotein particle and their components may be related to FVII activation (Mitropoulus et al., 1989) was supported in a human dietary intervention study that suggests chylomicron number and/or particle size is a determinant of FVII activation (Silva et al., 2003). In brief, MUFA-rich diets resulted in the formation of a smaller number of larger chylomicron particles and attenuated postprandial FVII activation. However, the mechanism by which lipoproteins could support FVII activation is not clear. It has also been hypothesised that the differential affinity of fatty acids for peroxisome proliferator activated receptor alpha (PPAR $\alpha$ ) (Lin et al., 1999), nuclear hormone receptors that play critical roles in regulating lipid 
metabolism, may help explain some of the differences in FVII activation, at least in the acute test meal situation.

\subsection{Other components in olive oil}

The proposed benefits of (extra virgin) olive oil may also relate to the presence of antioxidants such as phenolic compounds and vitamin $\mathrm{E}$.

\subsubsection{Phenolic compounds}

The effects of certain polyphenols in red wine, such as resveratrol and quercetin, have been widely investigated to determine the relationship between dietary phenolic compounds and the decreased risk of cardiovascular diseases in large population groups. However, the effects of polyphenols contained in other foods, such as extra virgin olive oil, have received less attention and little information exists regarding the biological activities of the phenol fraction in extra virgin olive oil.

The type and amount of phenolics present in extra virgin olive oil will depend on the origin of olives and processing technique employed. Olive oils tend to be classified into refined (without phenolic compounds), common (with low phenolic content) or extra virgin (with high phenolic content). The major phenolic compounds in extra virgin olive oil are oleuropein, hydroxytyrosol and tyrosol but at least 30 phenolic compounds can be present (Tuck and Hayball, 2002; see also issue 1).

Refined olive oil contains less phenolic compounds because during its production a large fraction of bioactive compounds present in olives is lost in mill waste-water. Because of the link between flavonoids and a reduced risk of $\mathrm{CHD}$, and to reduce any ecological problems linked to the disposal of such waste, different procedures are under investigation for the recovery of the active components of olive mill waste-water (www.flair-flow.com/health-docs/ffe59703.html). Although unpublished yet, this project has shown that hydroxytyrosol administered as a capsule reduces platelet aggregation. It is unclear at present whether lower doses, such as those in extra virgin olive oil produce the same effects.

Petroni et al. (1995) published the first evidence that components of the phenolic fraction of extra virgin olive oil inhibit platelet function and eicosanoid formation in vitro. 2-(3,4-di-hydroxyphenyl)-ethanol (DHPE), a phenol component of extra virgin olive oil decreased platelet agregation induced by ADP and collagen, and $\mathrm{TxB}_{2}$ production by collagen and thrombin-stimulated PRP. Oleuropein was less active in reducing PRP aggregation. In a recently published study two isochromans [1-(3'-methoxy-4'-hydroxy-phenyl)-6,7-dihydroxyisochroman and 1-phenyl-6,7-dihydroxy-isochroman], present in extra virgin olive oil, inhibited platelet aggregation and thromboxane release induced by AA and collagen, but not ADP (Togna et al., 2003). Beneficial effects have also been reported in human studies. The significant reduction in plasma $\mathrm{TxB}_{2}$ concentration after an extra virgin olive oil diet compared to a high-oleic sunflower oil diet was attributed in part to the greater amount of phenolics in the former diet (Oubina et al., 2001).

Elucidating the bioavailabilty of phenolic compounds is essential for understanding whether the in vitro effects occur in vivo. Indeed, there is evidence that tyrosol and hydroxytyrosol are absorbed and metabolised from realistic doses of extra virgin olive oil (Miro-Casas et al., 2003). However, the majority of studies have focused on their subsequent effect on oxidant/antioxidant status and not on markers of haemostasis. The phenolics in extra virgin olive oil are potent inhibitors of reactive oxygen species and they protect against lipid and lipoprotein oxidation in vitro (Fito et al., 2000). This effect may influence the tendency of thrombosis should the oxidisability of LDL affect platelet function as suggested by Siess et al. (1999).

\subsubsection{Vitamin $E$}

Vitamin $\mathrm{E}$ is an antioxidant nutrient that has the ability to reduce oxidative damage to LDL and other lipids. This in itself may influence platelet function (see above). Moreover, an inhibitory effect of vitamin $E$ on platelet function has been observed (Steiner, 1999) although the mechanisms of action may not relate to the antioxidant action of vitamin $E$ but rather to direct membrane effects (Steiner et al., 1997).

The disadvantage of studying the effects of olive oil-derived phenolics or vitamin $\mathrm{E}$ in vitro is that bioavailability and metabolism are not accounted for. Moreover, higher concentrations than those habitually consumed tend to be employed. Thus, the needs for human intervention studies rich in (extra virgin) olive oil are obvious but do not negate the importance of identifying the active components, their mechanism of action and efficacy. Both types of studies are a vital part of maximising the potential protective effects of (extra virgin) olive oil.

\section{CONCLUSION}

In the 1970s, Keys et al. (1986) provided ecological evidence that introduced the concept of a reduced risk for $\mathrm{CHD}$ associated with the traditional Mediterranean diet and a high intake of MUFA. Since then, there has been intense investigation to determine how (extra virgin) olive oil, a key component of the traditional Mediterranean diet, could contribute to these cardioprotective effects. Extra virgin olive oil is a rich source of MUFA and antioxidants. Both components mediate cardioprotective effects in a 
number of ways, including effects on blood lipids, inflammation and coagulation. The attenuation of the thrombotic response by long-term MUFA/olive oil diets is likely to occur through reduction in platelet aggregatory response and via a reduction in postprandial FVII levels. The latter may occur through actions of MUFA on the formation of chylomicrons, resulting in generation of larger particles but which are fewer in number. However, it should be emphasised that the efficacy and the mechanism of action of MUFA-rich diets and (extra virgin) olive oil on determinants of haemostasis are not clear at present. Nevertheless, based on the evidence to date, the potential for (extra virgin) olive oil to be beneficial appears significant.

The traditional Mediterranean diet contains an abundance of plant foods such as bread, pasta, vegetables, legumes and fruit with extra virgin olive oil as the principle source of fat. In many ways, it meets the dietary guidelines recommended in most countries; being low in SFA, rich in carbohydrates and fibre with large amounts of fruit and vegetables. It is this diet as an entity, and in combination with an active lifestyle, that is likely to be most beneficial to health.

On a final point, it is paradoxical that there appears to be an abandonment of the traditional way of eating in some Mediterranean areas, whereas olive oil is now popular with Northern Europeans. Because the prevalence of CVD risk across Europe may be changing, an EU-funded project called IMMIDIET is assessing the contribution of genes, dietary change and their interaction on any observed changes in CVD risk factors, including FVII in subjects from the UK, Italy and Belgium (www.flair-flow.com/health-docs/ffe58703.html). Dietgene interactions were not discussed in this review, but are likely to explain part of the discrepnacies between studies and will form an integral part of future interventions.

\section{REFERENCES}

Aird, W.C. (2003). Haemostasis and irreducible complexity. J. Thromb. Haemost., 1, 227-230.

Avellone, G., Di Garbo, V., Cordova, R., Scaffidi, L., Bompiani, G.D. (1998). Effects of Mediterranean diet on lipid, coagulative and fibrinolytic parameters in two randomly selected population samples in Western Sicily. Nutr. Metab. Cardiovasc. Dis., 8, 287-296.

Aviram, M., Brook, G.J. (1982). The effect of human plasma on platelet function in familial hypercholesterolemia. Thromb. Res., 26, 101-109.

Babior, B.M., Stossel, T.P. (1990a). Platelets. In Hematology: A Pathophysiological Approach, pp. 203-220. Churchill Livingston: New York.

Babior, B.M., Stossel, T.P. (1990b). The coagulation cascade and its regulation: Congenital and acquired clotting factor disorders. In Hematology: A Pathophysiological Approach, pp. 181-201 Churchill Livingston: New York.
Barradas, M.A., Christofides, J.A., Jeremy, J.Y., Mikhailidis, D.P., Fry, D.E., Dandona, P. (1990). The effect of olive oil supplementation on human platelet function, serum cholesterol-related variables and plasma fibrinogen concentrations: a pilot study. Nutr. Res., 10, 403-411.

Bauer, K.A. (1993). Laboratory markers of coagulation activation. Arch. Pathol. Lab. Med., 117, 71-77.

Bladbjerg, E.M., Munster, A.M., Marckmann, P., Keller, N., Jespersen, J. (2000). Dietary factor activation does not increase plasma concentrations of prothrombin fragment $1+2$ in patients with stable angina pectoris and coronary atherosclerosis. Arterioscler. Thromb. Vasc. Biol., 20, 2494-2499.

British Nutrition Foundation (1992). Unsaturated fatty acids, thrombogenesis and fibrinolysis. In Unsaturated fatty acids: Nutritional and Physiological Significance. The report of the British Nutrition Foundation's Task force, pp. 92-113. Chapman and Hall.

British Nutrition Foundation (2004). Task Force Report: Cardiovascular Disease: Diet, Nutrition and Emerging Risk Factors. (ed. S.Stanner). Oxford: Blackwell Publishing.

Byberg, L., Smedman, A., Vessby, B., Lithell, H. (2001). Plasminogen activator inhibitor- 1 and relations to fatty acid composition in the diet and in serum cholesterol esters. Arterioscler. Thromb. Vasc. Biol., 21, 2086-2092.

Carvalho, A.C.A., Colman, R.W., Lees, R.S. (1974). Platelet function in hyperlipoproteinemia. N. Engl. J. Med., 290, 434-438.

Cooper, J.A., Miller, G.J., Bauer, K.A., Morrissey, J.H., Meade, T.W., Howarth, D.M., Barzegar, S., Mitchell, J.P., Rosenberg, R.D. (2000). Comparison of novel hemostatic factors and conventional risk factors for prediction of coronary heart disease. Circulation, 102, 2816-2822.

Davie, E.W., Ratnoff, O.D. (1964). Waterfall sequence for intrinsic blood clotting. Science, 145, 1310-1312.

Elwood, P.C., Beswick, A., Pickering, J., McCarron, P., O'Brien, J.R., Renaud, S.R., Flower, R.J. (2001). Platelet tests in the prediction of myocardial infarction and ischaemic stroke: evidence from the Caerphilly Prospective Study. Br. J. Haematol., 113, 514-520.

Fitzgerald, G.A., Barry, P. (1997). Dietary factors in thrombosis and hemostasis: summary and conclusions. Am. J. Clin. Nutr., 65, 1699S-1701S.

Fito, M., Covas, M.I., Lamuela-Raventos, R.M., Vila, J., Torrents, L., de la Torre, C., Marrugat, J. (2000). Protective effect of olive oil and its phenolic compounds against low density lipoprotein oxidation. Lipids, 35, 633-638.

Finnegan, Y.E., Howarth, D., Minihane, A.M., Kew, S., Miller, G.J., Calder, P.C., Williams, C.M. (2003). Plant and marine derived ( $n-3)$ polyunsaturated fatty acids do not affect blood coagulation and fibrinolytic factors in moderately hyperlipidemic humans. J. Nutr., 133, 2210-2213.

Freese, R., Mutanen, M. (1995). Postprandial changes in platelet function and coagulation factors after high-fat meals with different fatty acid compositions. Eur. J. Clin. Nutr., 49, 658-664.

Freese, R., Mutanen, M., Valsta, L.M., Salminen, I. (1994). Comparison of the effects of two diets rich in monounsaturated fatty acids differing in their linoleic/ $\alpha$-linolenic acid ratio on platelet aggregation. Thromb. Haemost., 71, 73-77.

Foley, M., Ball, M., Chisholm, A., Duncan, A., Spears, G., Mann, J. (1992). Should mono- or poly-unsaturated 
fats replace saturated fat in the diet?. Eur. J. Clin. Nutr., 46, 429-436.

George, J.N. (2000). Platelets. Lancet, 355, 1531-1539.

Hamsten, A., Wallidius, G., Szamos, A., Blomback, M., de Faire, U., Dahlen, G., Landou, C., Wiman, B. (1987). Plasminogen activator inhibitor in plasma: risk factor for recurrent myocardial infarction. Lancet, 2, 3-8.

Hamsten, A., Wiman, B., deFaire, U., Blomback, M. (1985). Increased plasma level of a rapid inhibitor of tissue plasminogen activator in young survivors of myocardial infarction. N. Engl. J. Med., 313, 1557-1563.

Heinrich, J., Balleisen, L., Schulte, H., Assman, G., van de Loo, J. (1994). Fibrinogen and factor VII in the prediction of coronary risk: Results from the PROCAM study. Arterioscler. Thromb., 14, 54-59.

Heinrich, J., Wahrburg, U., Marting, H., Assman, G. (1990). The effect of diets, rich in mono- or poly-unsaturated fatty acids, on lipid metabolism and haemostasis. Fibrinolysis, 4, 76-78.

Hornstra, G., Rand, M.L. (1986). Influence of dietary lipids on platelet-vessel wall interaction: possible role of eicosanoids and platelet membrane fluidity. Haemostasis, 16, 41-42.

Huhle, G., Abletshauser, C., Mayer, N., Weidinger, G., Harenberg, J., Heene, D.L. (1999). Reduction of platelet activity markers in type II hypercholesterolemic patients by a HMG-CoA-reductase inhibitor. Thromb. Res., 95, 229-234.

Hussein, O., Rosenblat, M., Schlezinger, S., Keidar, S., Aviram, M. (1997). Reduced platelet aggregation after fluvastatin therapy is associated with altered platelet lipid composition and drug binding to the platelets. $\mathrm{Br}$. J. Clin. Pharmacol., 44, 77-84.

Joist, J.H., Baker, R.K., Schonfeld, G. (1979). Increased in vivo and in vitro platelet function in type II- and type IV-hyperlipoproteinemia. Thromb. Res., 15, 95-108.

Keys, A., Menotti, A., Karvonen, M.J., Aravanis, C., Blackburn, H., Buzina, R., Djordjevic, B.S., Dontas, A.S., Fidanza, F., Keys, M.H., Kromhout, D., Nedeljkovic, S., Punsar, S., Seccareccia, F., Toshima, $H$. (1986). The diet and 15-year death rate in the Seven Countries Study. Am. J. Epidemiol., 124, 903-915.

Kroll, M.H., Schafer, A.I. (1989). Biochemical mechanisms of platelet activation. Blood, 74, 1181-1195.

Kuller, L.H., Tracy, R.P., Shaten, J., Meilahn, E.N. (1996). Relation of C-reactive protein and coronary heart disease in the MRFIT nested case-control study, Multiple Risk Factor Intervention Trial. $A m$. J. Epidemiol., 144, 537-547.

Lindman, A.S., Muller, H., Seljeflot, I., Prydz, H., Veierod, M., Pedersen, J.I. (2003). Effects of dietary fat quantity and composition on fasting and postprandial levels of coagulation factor VII and serum choline-containing phospholipids. Br. J. Nutr., 90, 329-36.

Larsen, L.F., Jespersen, J., Marckmann, P. (1999). Are olive oil diets antithrombotic? Diets enriched with olive, rapeseed or sunflower oil affect postprandial factor VII differently. Am. J. Clin. Nutr., 70, 976-982.

Larsen, L.F., Bladbjerg, E.M., Jespersem, J., Marckmann, P. (1997). Effects of dietary fat quality and quantity on postprandial activation of blood coagulation factor VII. Arterioscler. Thromb. Vasc. Biol., 17, 2904-2909.

Lin, Q., Ruuska, S.E., Shaw, N.S., Dong, D., Noy, N. (1999). Ligand selectivity of the peroxisome proliferator-activated receptor alpha. Biochemistry, 5, 185-190.

Lopez-Segura, F., Velasco, F., Lopez-Miranda, J., Castro, P., Lopez-Pedrera, R., Blanco, A., Jimenez-Pereperez, J., Torres, A., Trujillo, J., Ordovas, J.M., Perez-Jimenez,
F. (1996). Monounsaturated fatty acid-enriched diet decreases plasma plasminogen activator inhibitor type 1. Arterioscler. Thromb. Vasc. Biol., 16, 82-88.

Macfarlane, R.G. (1964). An enzyme cascade in the blood clotting mechanism, and its function as a biochemical amplifier. Nature, 202, 498-499.

Ministry of Agriculture Fisheries and Food (1998). Fatty acids Supplement to McCance and Widdowson's The Composition of Foods. Royal Society of Chemistry, Cambridge and MAFF, London.

Mann, K.G. (1997). Thrombosis: theoretical considerations. Am. J. Clin. Nutr., 65, 1657S-1664S.

Marckmann, P. (1995). Diet, blood coagulation and fibrinolysis (thesis). Danish Medical Bulletin, 42, 410-425.

Marckmann, P., Bladbjerg, E.M., Jespersen, J. (1998). Diet and blood coagulation factor VII- a key protein in arterial thrombosis. Eur. J. Clin. Nutr., 52, 75-84.

McDonald, B.E., Gerrard, J.M., Bruce, V.M., Corner, E.J. (1989). Comparison of the effect of canola oil and sunflower oil on plasma lipids and lipoproteins and on in vivo thromboxane $A_{2}$ and prostacyclin production in healthy young men. Am. J. Clin. Nutr., 50, 1382-1388.

Meade, T., Ruddock, V., Stirling, Y., Chakrabarti, R., Miller, G.J. (1993). Fibrinolytic activity, clotting factors, and long term incidence of ischaemic heart disease in the Northwick Park Heart Study. Lancet, 342, 1076-1079.

Meade, T.W., Brozovic, M., Chakrabarti, R.P., Haines, A.P. Imeson, J.D., Mellows, S., Miller, G.J., North, W.R.S., Stirling, Y., Thompson, S.G. (1986). Hemostatic function and ischaemic heart disease: Principle results of the Northwick Park Heart Study. Lancet, 2, 533-537.

Meade, T.W., Vickers, M.V., Thompson, S.G., Stirling, Y., Haines, A.P., Miller, G.J. (1985). Epidemiological characteristics of platelet aggregability. Br. Med. J., 290, 428-432.

Meade, T.W., Chakrabarti, R., Haines, A.P., North, W.R.S., Stirling, Y. (1979). Characteristics affecting fibrinolytic activity and plasma fibrinogen concentration. Br. Med. J., 1, 153-156.

Miller, G.J., Martin, J.C., Mitropoulos, K.A., Esnouf, M.P., Cooper, J.A., Morrissey, J.H., Howarth, D.J., Tuddenham, E.G.D. (1996). Activation of factor VII during alimentary lipemia occurs in healthy adults and patients with congenital factor XII or factor XI deficiency, but not in patients with factor IX deficiency. Blood, 87, 4187-4196.

Miller, G.J., Stirling, Y., Howarth, D.J., Cooper, J.C., Green, F.R., Lane, A., Humphries, S. (1995). Dietary fat intake and plasma factor VII antigen concentration. Thromb. Haemost., 73, 893.

Miller, G.J., Martin, J.C., Mitropoulos, K.A., Reeves, B.E.A., Thompson, R.L., Meade, T.W., Cooper, J.A., Cruickshank, J.K. (1991). Plasma factor VII is activated by postprandial triglyceridaemia, irrespective of dietary fat composition. Atherosclerosis, 86, 163-171.

Miro-Casas, E., Covas, M.I., Fito, M., Farre-Albadalejo, M., Marrugat, J., de la Torre, R. (2003). Tyrosol and hydroxytyrosol are absorbed from moderate and sustained doses of virgin olive oil in humans. Eur. J. Clin. Nutr., 57, 186-190.

Mitropoulos, K.A., Miller, G.J., Martin, J.C., Reeves, B.E.A., Cooper, J. (1994). Dietary fat induces changes in factor VII coagulant activity through effects on plasma free stearic acid concentration. Arterioscler. Thromb., 14, 214-222.

Mitropoulos, K.A., Miller, G.J., Reeves, B.E., Wilkes, H.C., Cruickshank, J.K. (1989). Factor VII coagulant activity is strongly associated with the plasma concentration of 
large lipoprotein particles in middle-aged men. Atherosclerosis, 76, 203-208.

Mutanen, M., Freese, R., Valsta, L.M., Ahola, I., Ahlström, A. (1992). Rapeseed oil and sunflower oil diets enhance platelet in vitro aggregation and thromboxane production in healthy men when compared with milk fat or habitual diets. Thromb. Haemost., 67, 352-356.

National Heart Forum (2002). Coronary heart disease: Estimating the impact of changes in risk factors. London: The Stationery Office.

Noula, C., Bonzom, P., Brown, A., Gibbons, W.A., Martin, J., Nicolau, A. (2000). ' H-NMR profiles of human blood. Biochim. Biophys. Acta, 1487, 15-23.

Oakley, F.R., Sanders, T.A.B., Miller, G.J. (1998). Postprandial effects of an oleic acid-rich oil compared with butter on clotting factor VII and fibrinolysis in healthy men. Am. J. Clin. Nutr., 68, 1202-1207.

Oubina, P., Sanchez-Muniz, F.J., Rodenas, S., Cuesta, C. (2001). Eicosanoid production, thrombogenic ratio, and serum and LDL peroxides in normo- and hypercholesterolaemic post-menopausal women consuming two oleic acid-rich diets with different content of minor components. Br. J. Nutr., 85, 41-47.

Patrono, C., Ciabattoni, G., Pinca, E., Pugliese, F., Castrucci, G., De Salvo, A., Satta, M.A., Peskar, A. (1980). Low dose aspirin and inhibition of thromboxane B2 production in healthy subjects. Thromb. Res., 17, 317-327.

Payne, D.A., Hayes, P.D., Jones, C.I., Belham, P., Naylor, A.R., Goodall, A.H. (2002). Combined therapy with clopidogrel and aspirin significantly increases the bleeding time through a synergistic antiplatelet action. J. Vasc. Surg., 36, 1204-1209.

Petroni, A., Blasevich, M., Salami, M., Papini, N., Montedoro, G., Galli, C. (1995). Inhibition of platelet aggregation and eicosanoid production by phenolic compounds of olive oil. Thromb. Res., 78, 151-160.

Rayner, M., Petersen, S. (2000). European cardiovascular disease statistics. British Heart Foundation: London.

Ridker, P.M., Hennekens, C.H., Stampfer, M.J., Manson, J.E., Vaughan, D.E. (1994). Prospective study of endogenous tissue plasminogen activator and risk of stroke. Lancet, 343, 940-943.

Ridker, P.M., Vaughan, D.E., Stampfer, M.J. (1993). Endogenous tissue-type plasminogen activator and risk of myocardial infarction. Lancet, 341, 1165-1168.

Roche, H.M., Zampelas, A., Knapper, J.M.E., Webb, D., Brooks, C., Jackson, K.G., Wright, J.W., Gould, B.J., Kafatos, A., Gibney, M.J., Williams, C.M. (1998). Effect of long-term olive oil dietary intervention on postprandial triacylglycerol and factor VII metabolism. Am. J. Clin. Nutr., 68, 552-560.

Roche, H.M., Gibney, M. (1997). Postprandial coagulation factor VII activity: the effect of monounsaturated fatty acids. Br. J. Nutr., 77, 537-549.

Sanders, T.A., Oakley, F.R., Crook, D., Cooper, J.A., Miller, G.J. (2003). High intakes of trans monounsaturated fatty acids taken for 2 weeks do not influence procoagulant and fibrinolytic risk markers for CHD in young healthy men. Br. J. Nutr., 89, 767-776.

Sanders, T.A., de Grassi, T., Miller, G.J., Humphries, S.E. (1999). Dietary oleic and palmitic acids and postprandial factor VII in middle-aged men heterozygous and homozygous for factor VII R353Q polymorphism. Am. J. Clin. Nutr., 69, 220-225.

Salomaa, V., Rasi, V., Pekkanen, J., Salomaa, V., Rasi, V., Pekkanen, J., Jauhiainen, M., Vahtera, E., Pietinen, P., Korhonen, H., Kuulasmaa, K., Ehnholm, C. (1993). The effects of saturated fat and $n-6$ polyunsaturated fat on postprandial lipemia and hemostatic activity. Atherosclerosis, 103, 1-11.

Schmaier, A.H. (2002). The plasma kallikrein-kinin system counterbalances the renin-angiotensin system. J. Clin. Invest., 109, 1007-1009.

Shariat-Madar, Z., Mahdi, F., Schmaier, A.H. (2002). Assembly and activation of the plasma kallikrein/kinin system: a new interpretation. Int. Immunopharmacol., 2, 1841-1849.

Siess, W., Zangl, K.J., Essler, M., Bauer, M., Brandl, M., Corrinth, C., Bittman, R., Tigyi, G. (1999). Lysophosphatidic acid mediates the rapid activation of platelets and endothelial cells by mildly oxidized low density lipoprotein and accumulates in human atherosclerotic lesions. Proc. Natl. Acad. Sci. USA, 96, 6931-6936.

Silva, K.D.R.R., Kelly, C.N.M., Jones, A.E., Smith, R.D., Wootton, S.A., Miller, G.J., Williams, C.M. (2003). Chylomicron particle size and number, factor VII activation and dietary monounsaturated fatty acids. Atherosclerosis, 166, 73-84.

Silveira, A. (2001). Postprandial triglycerides and blood coagulation. Exp. Clin. Endocrinol. Diabetes, 109, S527-S532.

Silveira, A., Karpe, F., Blomback, M., Steiner, G., Walldius, G., Hamsten, A. (1994). Activation of coagulation factor VII during alimentary lipemia. Arterioscler. Thromb., 14, 60-69.

Sirtori, C.R., Tremoli, E., Gatti, E., Montanari, G., Sirtori, M., Colli, S., Gianfranceschi, G., Maderna, P., Dentone, C.Z., Testolin, G., Galli, C. (1986). Controlled evaluation of fat intake in the Mediterranean diet: comparative activities of olive oil and corn oil on plasma lipids and platelets in high-risk patients. Am. J. Clin. Nutr., 44, 635-642.

Smith, R.D., Kelly, C.N., Fielding, B.A., Hauton, D., Silva, K.D., Nydahl, M.C., Miller, G.J., Williams, C.M. (2003) Long term monounsaturated fatty acid diets reduce platelet aggregation in healthy young subjects. Br. J. Nutr., 90, 597-606.

Steiner, M. (1999). Vitamin E, a modifier of platelet function: Rationale and use in cardiovascular and cerebrovascular disease. Nutr. Rev., 57, 306-309.

Steiner, M., Li, W., Ciaramella, J.M., Testa, U. (1997). DL-alpha-tocopherol, a potent inhibitor of phorbol ester induced change of erythro- and megakaryoblastic leukaemia cells. J. Cell. Physiol., 172, 351-360.

Stuart, M.J., Gerrard, J.M., White, J.G. (1980). Effect of cholesterol on production of thromboxane $B_{2}$ by platelets in vitro. N. Engl. J. Med., 302, 6-10.

Temme, E.H.M., Mensink, R.P., Hornstra, G. (1999). Effects of diets enriched in lauric, palmitic or oleic acids on blood coagulation and fibrinolysis. Thromb. Haemost., 81, 259-263.

The Antiplatelet Trialists Collaboration (2002). Collaborative meta-analyses of randomised trials of antiplatelet therapy for prevention of death, myocaridal infarction, and stroke in high risk patients. Br. Med. J., 324, 71-86.

The Anti-platelet Trialists Collaboration (1994). Collaborative overview of antiplatelet therapy I: Prevention of death, myocardial infarction and stroke by prolonged anti-therapy in various categories of patients. Br. Med. J., 308, 81-100.

Togna, G.I., Togna, A.R., Franconi, M., Marra, C., Guiso, M. (2003). Olive oil isochromans inhibit human platelet reactivity. J. Nutr., 133, 2532-2536.

Tholstrup, T., Miller, G.J., Bysted, A., Sandstrom, B. (2003). Effect of individual dietary fatty acids on postprandial 
activation of blood coagulation factor VII and fibrinolysis in healthy young men. Am. J. Clin. Nutr., 77, 1125-1132.

Tholstrup, T., Marckmann, P., Hermansen, J., Hølmer, G., Sandström, B. (1999). Effect of modified dairy fat on fasting and postprandial haemostatic variables in healthy young men. Br. J. Nutr., 82, 105-113.

Tholstrup, T., Marckmann, P., Jespersen, J., Sandström, B. (1994). A fat high in stearic acid favoroubly affects blood lipids and factor VII coagulant activity in comparison to fats high in plamitic acid and high in myristic and lauric acid. Am. J. Clin. Nutr., 59, 371-377.

Topol, E.J., Byzova, T.V., Plow, E.F. (1999). Platelet GPIlb-Illa blockers. Lancet, 353, 227-231.

Trip, M.D., Cats, V.M., VanCapelle, F.J.L., Vreeken, J. (1990). Platelet hyperactivity and prognosis in survivors of myocardial infarction. N. Engl. J. Med., 322, 1549-1554.

Tracy, R.P., Arnold, A.M., Ettinger, W., Fried, L., Meilahn, E., Savage, P. (1999). The relationship of fibrinogen and factors VII and VIII to incident cardiovascular disease and death in the elderly; results from the Cardiovascular Health Study. Arterioscler. Thromb. Vasc. Biol., 19, 1776-1783.

Tuck, K.L., Hayball, P.J. (2002). Major phenolic compounds in olive oil: metabolism and health effects. J. Nutr. Biochem., 13, 636-644.
Turpeinen, A.M., Mutanen, M. (1999). Similar effects of diets high in oleic or linoleic acids on coagulation and fibrinolytic factors in healthy humans. Nutr. Metab. Cardiovasc. Dis., 9, 65-72.

Turpeinen, A.M., Pajari, A.M., Freese, R., Sauer, R., Mutanen, M. (1998). Replacement of dietary saturated by unsaturated fatty acids: effects on platelet protein kinase $C$ activity, urinary content of 2,3-dinor-Tx $B_{2}$ and in vitro platelet aggregation in healthy man. Thromb. Haemost., 80, 649-655.

Vicario, I.M., Malkova, D., Lund, E.K., Johnson, I.T. (1998). Olive oil supplementation in healthy adults: effects in cell membrane fatty acid composition and platelet function. Ann. Nutr. Metab., 42, 160-169.

Wilhelmsen, L., Svardsudd, K., Korsan-Bengtsen, K., Larsson, B., Welin, L., Tibblin, G. (1984). Fibrinogen as a risk factor for stroke and myocardial infarction. $N$. Engl. J. Med., 311, 501-505.

Zampelas, A., Roche, H., Knapper, J.M.E., Jackson, K.G., Tornaritis, M., Hatzis, C., Gibney, M.J., Kafatos, A., Gould, B.J., Wright, J., Williams, C.M. (1998). Differences in postprandial lipaemic response between Northern and Southern Europeans. Atherosclerosis, 139, 83-93.

Zilversmit, D.B. (1979). Atherogenesis: A postprandial phenomenon. Circulation, 60, 473-485. 